\title{
Spanish researchers reject xeno moratorium...
}

A fight has erupted between the Council of Europe's Parliamentary Assembly and Spanish scientists over a February report by the council calling for a moratorium on clinical trials of xenotransplantation. Leading researchers in Spain-a country with one of the largest organ transplant programs in the world-have announced their opposition to the decision and their determination to press ahead with research in this area. This has prompted Gian-Retto Plattner, spokesperson for the council's bioethics committee, to condemn the researchers as being "motivated more by egoism and competition with the US than by the principles of precaution established in the report."

Rafael Matesanz, head of the Spanish Commission on Xenotransplantation and chair of the European Council's Transplantation Commission, describes the Council of Europe's motion as "a political and inappropriate decision, which did not take into account the opinion of technical and ethical specialists, who would have never recommended a moratorium."

Spain has one of only three teams worldwide developing procedures to transplant whole pig organs into baboons; the other two are Gilda Chávez's group at the University of Cambridge and Jeff Platt Duke's team at the Mayo Clinic. The Spanish research group, led by Rafael Máñez at the Hospital Juan Canalejo in La

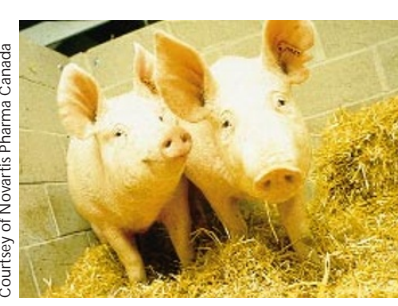

Transgenic pigs Coruña, is funded in part by the pharmaceutical company, Novartis. La Coruña has become the first European facility to import transgenic pigs, and has bought 36 genetically modi-

National transplantation rates

Country

RPMP 1992

Austria

Spain

Belgium

25.2

21.7

19.0

United States

France

U.K.

Canada

17.7

17.0

15.5

12.1

12.0

RPMP=rate per million population Courtsey of Novartis Pharma Canada fied animals from Novartis' British-based xenotransplant subsidiary Imutran, since April 1998.

Máñez's team has achieved xenograft survival times of 20-30 days, and its goal is to start phase I clinical trials when a minimum survival time of six months has been reached, obviously accompanied by the lack of any viral infection during this period.

Novartis funds a second Spanish xenotransplantation re search team, based at Hospital Virgen de la Arrixaca in Murcia and led by Pascual Parrilla, which also receives financial backing from a pork foodstuffs company.

M atesanz insists that Spanish guidelines on xenotransplantation assays are among the most

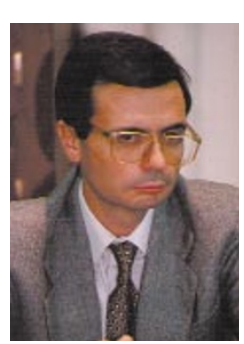

Rafael Matesanz clinical results on xenotransplantation will be obtained within the next two years.

But Plattner maintains that it is "impossible to know whether there will be transmission of a viral infection within six months." He says "many retroviruses take decades to appear, and the Spanish conditions are insufficient and therefore dangerous." The two sides have agreed to meet this month to discuss their differences.

Meanwhile, the Spanish Ministery of Health $(\mathrm{MoH})$ has also rejected the council's moratorium. Blanca Miranda, head of Spain's National Transplantation Organization, an $\mathrm{MoH}$ body, agrees with Matesanz: "it has been decision made by politicians withrigorous and cautious in the world (Nature Med. 4, 876; 1998). He admits he is concerned that a moratorium will cause Europe to lag behind the US. Furthermore, he says "this is a very untimely moment to give such a recommendation due to the critical stage of xenotransplantation research, namely short survival times of xenografts, and potential competition with the field of stem-cell research." He hopes the first set of pre out the advice of specialists," she told Nature Medicine. Moreover, she says that it has caused "an unnecessary social alarm, triggered by only one Oxfordbased scientist who discovered that porcine endogenous retroviruses could grow in cultured human cells" (Nature Med., 3, 282; 1997). Data on the Spanish public's perception of transplantation, obtained from a survey by Miranda's group, will be released this month.

XaVier Bosch, Barcelona

\section{...while Canada faces the issue head-on}

Canada is rapidly becoming an international leader in xenotransplantation. The country's xenotransplantation research activity has intensified over the last 12 months and now the Canadian government is gearing up to run a public consultation exercise on animalto-human transplants, in addition to developing an international thinktank on the procedure.

Based on the recommendations of the National Forum on Xenotransplantation held in Ottawa in November 1997 and sponsored by Health Canada, the country's national health body, Canada will host a gathering of international experts on xenotransplantation in Meech Lake, Quebec, in mid-June.

This preliminary meeting-to be cochaired by Stachan Donnelly of the Hastings Center in New York State, and Fark- honda Hassan, a member of the Senate of Egypt-will establish a mandatefor a twoyear, international panel on xenotransplantation. The panel will comprise $12-15$ individuals from around the world, and is expected to hold its first meeting in September.

Most of the planning for the June meeting has been done by veterinarian Betsy MacGregor, coordinator of Industry Canada's National Biotechnology Advisory Committee, and Fritz Bach of Harvard Medical School. Such is the commitment of the Canadian government to establishing a policy on xenotransplantation that in addition to Health Canada's sponsorship of the M eech Lake meeting, it is also financing the public consultation exercise, which is due to report its findings in 18 months. Furthermore, Industry Canada, another arm of the government, is funding a two-year sabbatical for Mac- 